\title{
WOOD ANATOMY NEWS
}

\section{Report from the 'Meeting on Periodicity of Growth in Tropical Trees', Kuala Lumpur, Malaysia}

This meeting was organized by the Forest Research Institute Malaysia in Kepong (FRIM), the IUFRO, the Federal Research Center for Forestry and Forest Products in Hamburg (BFH), and the German Association for Technical Cooperation (GTZ). It was held in Kuala Lumpur, 16-18 November 1994, with the aim of bringing together scientists of different fields of work within the theme of this meeting. IUFRO president and Director-General FRIM, Dr. Salleh Mohd. Nor, opened the meeting and confirmed the importance of research in age and growth rate determination in tropical trees. Twenty-four participants from ten countries presented results on several topics under the critical eyes of Alain Mariaux, during the meeting often named as one of the 'godfathers' of growth periodicity research. In four sessions the contributions dealt with both methodology in determination of growth rates and mainly relations to climate data. Studies on Tectona grandis and dipterocarps have been the main focus during this meeting. Pieter Baas offered the opportunity to submit all the papers to the IAWA Journal, in order to publish them by the end of 1995 in a special issue.

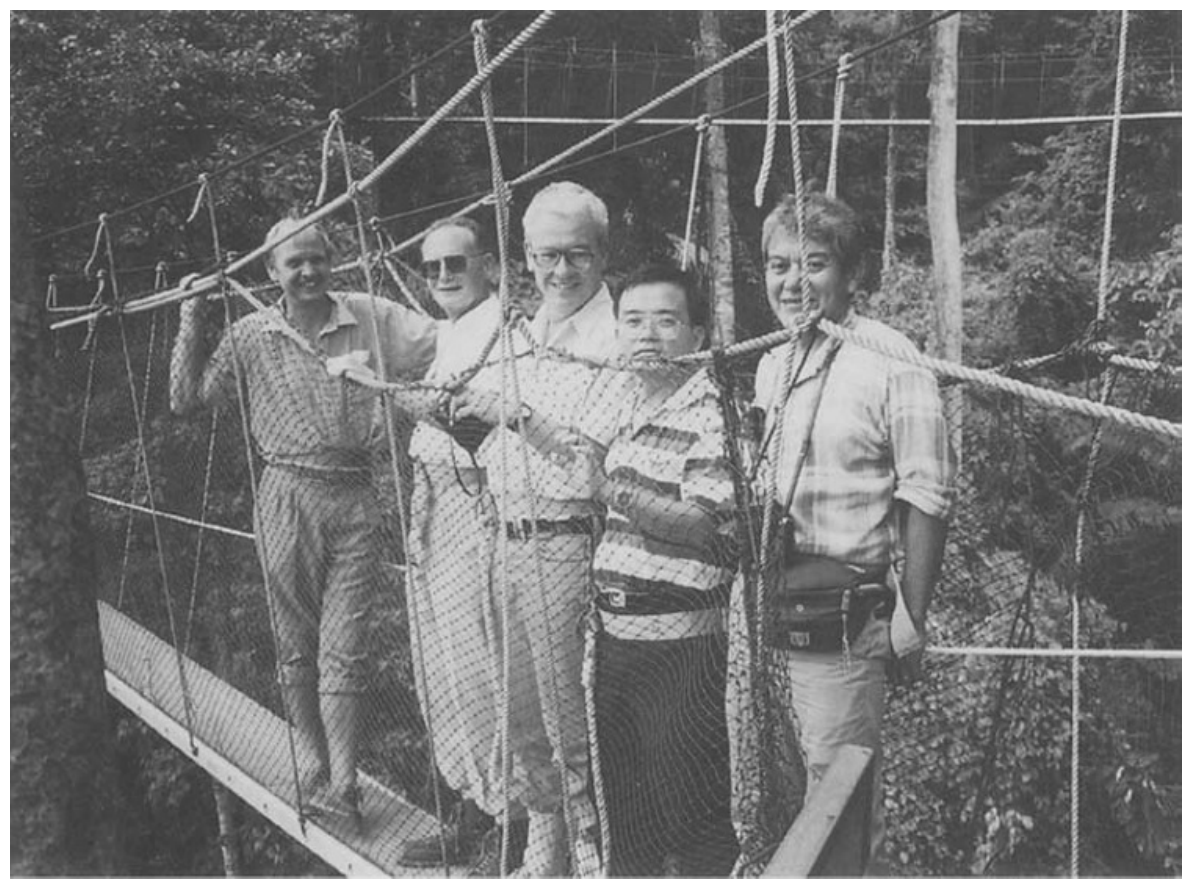

Three meeting organizers, one godfather, and a delegate; from left to right: Wulf Killmann, Alain Mariaux, Dieter Eckstein, Lim Seng Choon, and L. A. Pérez Jiménez, enjoying the canopy walk of the FRIM campus during the final day of the Growth Periodicity meeting in Kuala Lumpur. 
The reactivation of IUFRO subgroup 'Age and Growth Rate Determination in Tropical Trees' was recommended by the participants so as to achieve a closer cooperation between the different working groups.

During the congress dinner the participants highly enjoyed the delicious tastes of Malayan food. The meeting ended with a very impressive field excursion to FRIM ground and its in the meanwhile famous canopy walkway. Congratulations and many thanks for this well-organized meeting to Hong Lay Thong and Lim Seng Choon (FRIM), Wulf Killmann (GTZ), and Dieter Eckstein (BFH).

Uwe Schmitt, Hamburg

\section{Report from the Third Pacific Regional Wood Anatomy Conference at Rotorua, New Zealand}

The third Pacific Regional Wood Anatomy Conference was held at the New Zealand Forest Research Institute Ltd., Rotorua, New Zealand, on November 20-24, 1994. The conference site was a very airy, pleasant city with many hot springs in the middle of the North Island of a country which is populated firstly by sheep, secondly by cattle, and lastly by kiwis and human beings. About half of the delegates represented a short-term exodus from an over-populated country on the other side of the Pacific (undoubtedly lured by a craving for bathing in hot spas as well as wood anatomical information), the other half represented delegates from as many as 16 countries, who must also have shared the same desires.

In contrast with the by-necessity militaristic time-table of the sessions at last year's International Botanical Congress (IBC) at Yokohama, Japan, we could enjoy a very relaxed exchange of opinions, thanks to a flexible time-table with ample time for presentations and discussions, and due observance of tea-breaks with delicious sweets.

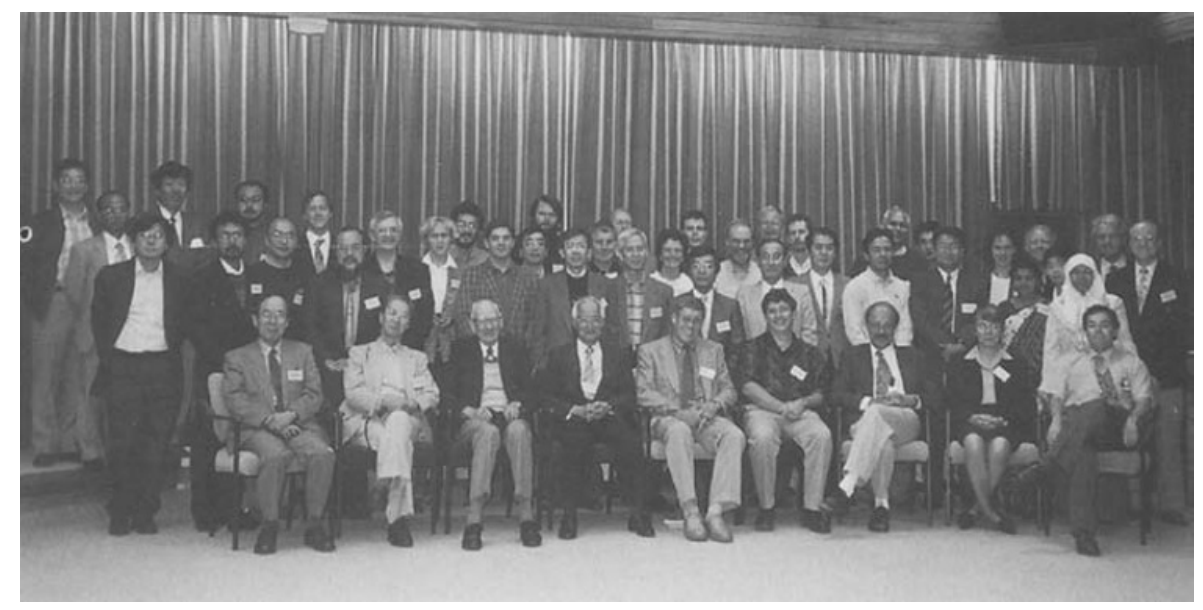

Delegates of the Third PRWAC in the meeting room of the New Zealand forest Research Institute Ltd. at Rotorua (Photo Lloyd Donaldson). 


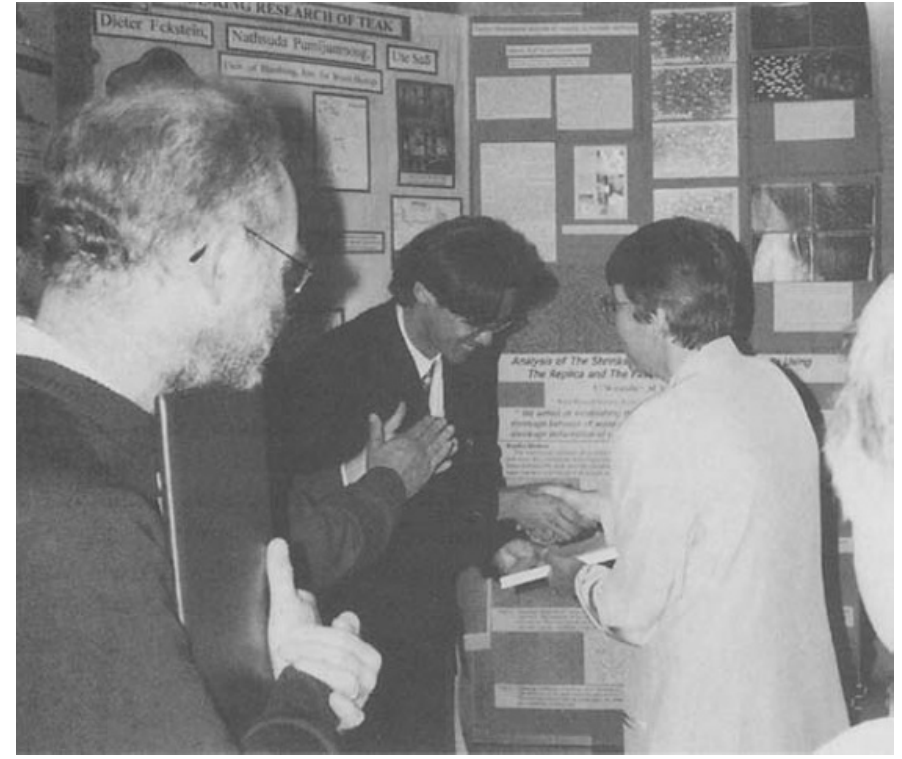

Dr. Ugai Watanabe receives the award for the best poster from Elisabeth Wheeler (Photo by T. Fujii).
The sessions began with a plenary lecture by Ken Shimaji. He introduced us to the timber usage in Japan since prehistoric times with photos of ancient wooden temples in Nara, reminiscent of the final day of last year's 'Hinoki' excursion after the IBC. A historical perspective is usually lacking in wood anatomy, and species selection in the ancient world can be a good stimulus for finding other criteria in wood property selection. A poster session was held in the evening of the first day with New Zealand wine and cheese as a promotor for frank discussions; this had a good effect and resulted in the ringing of the session hall with discussions by elated delegates. A prize was presented to Ugai Watanabe, Minoru Fujita, and Misato Norimoto for their poster on the integrated employment of traditional and latest methods in analysing shrinkage deformation of cells.

In the afternoon of the second day, a planned visit to Waiotapu Geothermal Reserve was canceled formally because of heavy rain, but perhaps also because of the reactions of some delegates to the prevailing smell of sulphur from the hot springs. Instead we visited the 'Agrodome' and enjoyed a lecture on breeds of sheep (many), and saw demonstrations of an efficient way of sheep shearing, and the shepherd's way of communication with his dogs by whistling. After the show some of the delegates went up on stage and were happy to be welcomed on both sides by several representatives of the main hairy populace (sheep) of New Zealand.

The third day began with another plenary lecture, by Michael Bariska. His video presentation of real-time fracture propagation under a scanning electron microscope was very realistic, and one felt as if one were in Brobdingnag, a land of giants in Jonathan Swift's “Gulliver's Travels", while observing microscopic fracture processes. In the evening, a conference dinner was held in a restaurant on a hill overlooking the huge caldera embracing Rotorua City and Lake Rotorua. This day happened to be the birthday of the Executive Secretary of IAWA, Ben ter Welle, and all present congratulated our very competent leader on this occasion and thanked him for his thirteen years of service to IAWA. 


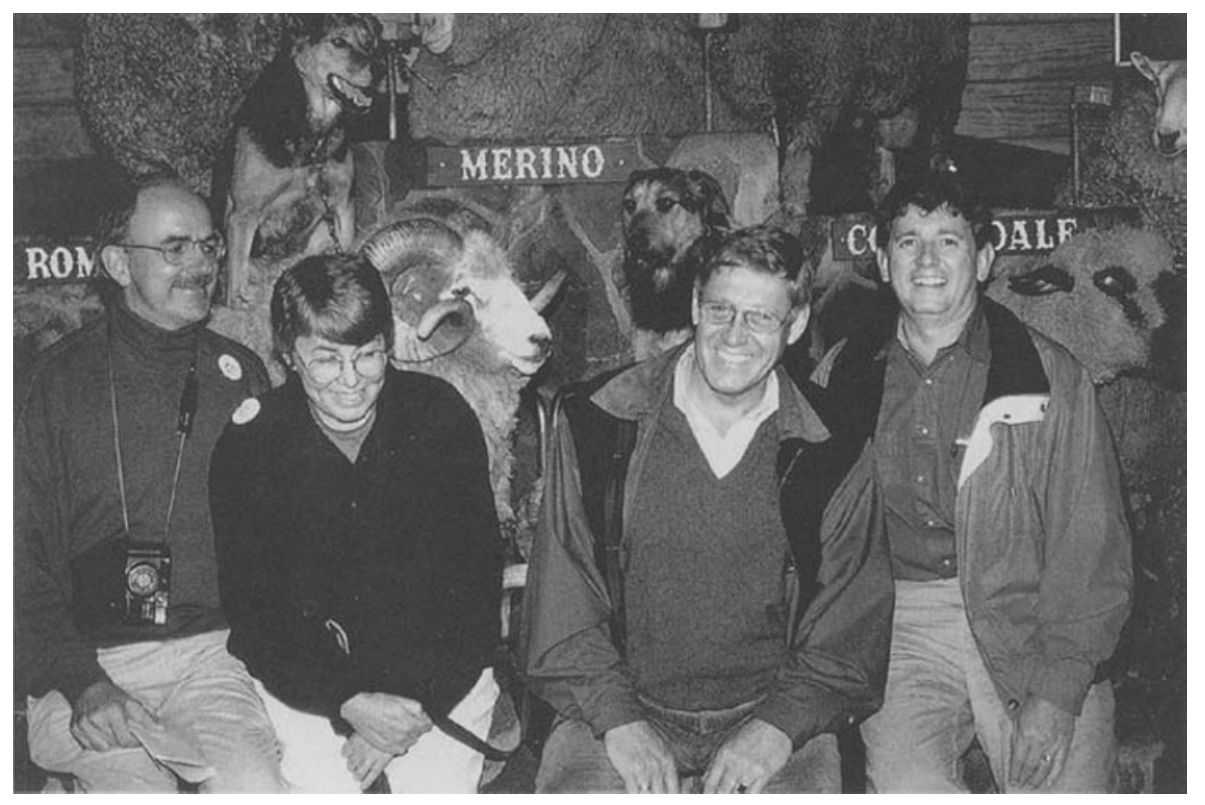

"For we like sheep" - the IAWA mafia (from left to right): Pieter Baas, Elisabeth Wheeler, Ben ter Welle and Regis Miller, mixing with sheep and sheep dogs at the Agrodome (Photo Peter Gasson).

In the IAWA business meeting on the fourth day, presided over by bosses of IAWA Mafia, the change in the IAWA Journal lay-out to a single column format with a slightly larger lettertype was announced, and suggested to be useful for improving readability for the aging membership of this association, and an invitation from Korean delegates of the next PRWAC to Cheju-do island in 1998 was approved by those present.

Success of this fruitful conference depended largely on the mindful arrangement of the organizing committee, especially the effusive and amusing Brian Butterfield and the quiet but very efficient Lloyd Donaldson.

Shuichi Noshiro \& Tomoyuki Fujii, Japan 